\title{
Scale Development Procedure for Cloud Computing Adoption
}

\author{
[Pragati Priyadarshinee, Prof. M.K. Jha, \& Prof. Rakesh D. Raut]
}

\begin{abstract}
This paper presents a study to develop and validate the model for Cloud computing adoption in Indian Industries. The data collected from 110 respondents and the analysis yielded important findings that state the research hypotheses. It is interesting to note in the study that one item; 'Usability' is dropped from the proposed model. Discussion on reasons for insignificant effect of this item on the construct, and there by resulting being dropped would add value to this research output. During the data analysis two variables; 'Top management support' and 'Marketplace establishment' in the construct Cloud computing adoption (CCA) showed very poor result. So, to get significant output, these two items were dropped temporarily. Hence, we need to verify these two items with the final sample size as they contain strong literature support. All these major findings of the reliability and Confirmatory Factor Analysis (CFA) shared with the experts before taking any decision.
\end{abstract}

Keywords-Cloud computing, Adoption, CFA, Validation, Hypotheses, Variable

Pragati Priyadarshinee

National Institute of Industrial Engineering

India

Prof. M.K. Jha

National Institute of Industrial Engineering India

Prof. Rakesh D. Raut

National Institute of Industrial Engineering India

\section{Introduction}

Cloud computing is meant to serve the businesses by increasing the performance, reducing the cost, increasing the storage capacity and easy accessibility worldwide. It can benefit most of the small and medium size enterprises (SMEs) in the starting phase of business expansion. Cloud computing develops in current years as a key to the IT dilemma with the growth of new IT and web technologies. It permits organizations to practice a pool of IT capitals and tenders as amenities almost through the web, deprived of physically holding these computing assets within (Dutta et al., 2013).

\section{Need of the Study}

The present study is based on empirical research. It is a mixture of both qualitative and quantitative research. The research produces solutions for a better performance of Indian organizations. The aim is to take theoretical insights and confirm these in real-world situations. Both qualitative and quantitative data are used. We will summarize and access the main benefits of cloud adoption in order to judge the performance of organizations to a specific situation or in a range of contexts.

The need of this study is to check the reliability and validity of the variables used in the instrument. Validity is the measure of the correctness of an instrument used in a study. Variable validity refers to "the perpendicular communication between a variable which is at an unobservable, theoretical level and an unsupported measure of it which is at an operative level" (Peter, 1981). It finds agreement between a theoretical concept and a specific measuring procedure. It establishes relations between latent (unobserved) variables and several observable items.

One way to check validity of the variables is to decide convergent validity and discriminant validity. Convergent validity gives pointer of a definite variable should part a high percentage of variance. Convergent validity was tested by confirming all average variance extracted (AVE) values more than 0.5 and factor loadings (Hair et al. 1998, Fornell \& Larcker, 1981). Discriminant validity was attained by connecting the common variance between variables with the average variance extracted from the different variables (Fornell \& Larcker, 1981).

Cronbach's alpha is the most commonly used estimator of the reliability of scales. Though, it has been evaluated as being a poorer bound and henceforth considerate true reliability. A general substitute to constant alpha is composite reliability, which is usually designed in grouping with structural equation modeling (Peterson \& Kim 2013). The average composite reliability value is always better than the average equivalent constant alpha.

\section{Objective of the Study}

The aim of the current study is to propose a framework for understanding the impact of Cloud Computing adoption on business performance and about the Questionnaire framed for measuring the effect.

Cloud computing is a paradigm shift which needs to understand how to adopt the technology. It is important to know companies' insights of Cloud computing and technology adoption because it can be used to define the 
factors those are likely to impact the performance of business.

Connecting to the problem statement, this study will focus on Industries who want to adopt or already adopted Cloud computing. Accepting the relationships between the different variables will help us recognize which ones impact more the business performance. The study will form on tested notions in technology acceptance to define which variables play a major role in defining Cloud adoption. In view of how different variables relate to business performance through Cloud adoption, this study has the following objectives:

1. Identify variables to measure business performance through Cloud computing adoption.

2. Examine the variables impacting the business performance through Cloud computing adoption.

3. Validate the scale developed to measure business performance through Cloud computing adoption.

4. Calculate the reliability of the scale.

\section{Research Methodology}

Exploratory study approach is used for this study. Qualitative and quantitative research approaches will be used to enhance the validity of findings. Constructs and variables are identified from the literature. Expert opinions are invited to confirm whether the identified constructs are best suited to measure business performance through cloud computing adoption. A two stage research methodology was recycled for the study. An actual instrument should shield the content area of each variable.

The items that quantity a variable should approve with each other and the items of one variable should differ with methods of the other variables. Each variable should be consistent and undersized and easy to practice. Scale development and improvement is a two-step method.

\section{A. Research Model and Hypotheses}

The study covers 9 major variables; 7 are independent variables, one mediator variable and one dependent variable. A mediator variable is the variable that affects mediation in the dependent and the independent variables. It describes the relationship between the dependent variable and the independent variable. A mediating variable is one that deceits between independent contributory factors and a final result. In statistics, mediating variable that communicates the indirect effects of an independent variables on a dependent variable. Usually, a given variable may be hypothetical to function as a mediator to the level that it accounts for the relation between the conjecturer and the standard. Mediators explain how outside physical proceedings take on interior psychological consequence (Barron \& Kenny, 1986). An unplanned or mediated result suggests that the independent variable affects the mediator, which, in turn affects the dependent variable (Holland, 1988).

Research hypotheses are framed and accessible in this section. Hypothesis testing is done to describe the nature of definite relationships, to create the variances between groups or to form the independence of more variables in a study (Sekaran, 1992).A hypothesis is a "logically estimated relationship between two or more variables stated in the arrangement of a testable statement" (Sekaran, 1992).Relationships are confirmed on the basis of the network of relations recognized in the conceptual model articulated for the research study. It is anticipated that solutions can be found to correct the problem met if the hypothesis is "statistically significant".

\section{Hypotheses:}

H1: There is a significant relationship between Perceived IT Security Risk and Cloud Computing Adoption.

$\mathrm{H} 2$ : There is a significant relationship between Risk Analysis and Cloud Computing Adoption.

H3: There is a significant relationship between Technology Innovation and Cloud Computing Adoption.

$\mathrm{H} 4$ : There is a significant relationship between Usage of Technology and Cloud Computing Adoption.

H5: There is a significant relationship between Industry Usage and Cloud Computing Adoption.

H6: There is a significant relationship between Trust and Cloud Computing Adoption.

H7: There is a significant relationship between Management Style and Cloud Computing Adoption.

H8: There is a significant relationship between Cloud Computing Adoption and Business Performance.

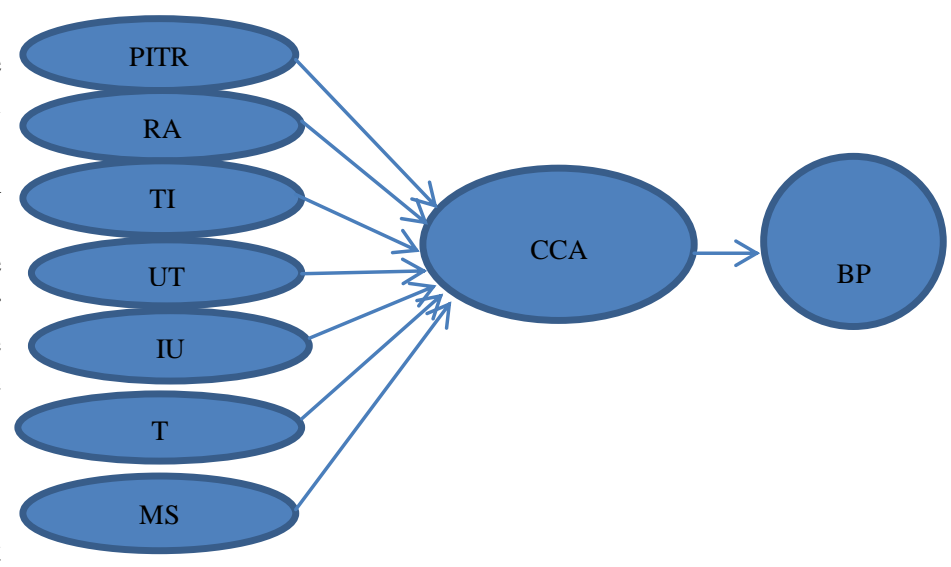

Figure 1: Research Model

PITR $=$ Perceived IT Security Risk

$\mathrm{RA}=$ Risk Analysis

$\mathrm{TI}=$ Technology Innovation

UT = Usage of Technology

$\mathrm{IU}=$ Industry Usage

$\mathrm{T}=$ Trust

MS = Management Style

$\mathrm{CCA}=$ Cloud Computing Adoption

$\mathrm{BP}=$ Business Performance

\section{B. Measurement Scale Development}

Survey based method is used to measure business performance through cloud computing adoption. A survey instrument which questionnaire is designed to operationalize the measures of 9 constructs of Cloud computing adoption. Both qualitative and quantitative questionnaire is prepared. To measure each of the constructs, items are prepared for each construct.

The survey instrument was intended for participants to specify arrangement on certain accounts. The questionnaire also had segments for demographic information such as: 
Name, E-mail Id, Organizational Position, Years of Experience, Annual Turnover and Type of Industry.

Initially the definitions of the variables as well as the measurement items for each variable were recognized. In this phase, an uncertain suggestion of reliability and validity was also provided. It included item generation, pre-pilot study, and pilot study.

The second phase will be the final survey and model validation. This report focuses on the findings of the reliability and Confirmatory Factor (CFA) Analysis based on pilot study of 110 respondents. Based on the validated scales the questionnaire for the final survey will be modified.

\section{Sample Design and Data Collection}

For the purpose of this Study, data was collected by two main ways. In the first method, a series of informal interviews was conducted with three individuals from organizations' IT Department, including two directors and a service manager. The second method of data collection was to search the organizations' internal portal to examine and analyze relevant information pertaining to risk associated with Cloud computing adoption. A total of 15 personnel from 5 organizations were involved in the study that was perceived to be a key part of information security process at their respective company. The interviews were open-ended and discovery oriented with a well-defined focus for systematic data collection. All the interviews lasted between $45-75$ minutes.

The manufacturing, service and process organizations were selected from Bombay Chamber of Commerce and Industry. Only those companies were included in the survey who were found engaged in cloud computing services. Companies qualifying the criterion were contacted for the survey.

\section{v. Results}

Table 1: Cronbach's Alpha Calculation

\begin{tabular}{|c|c|}
\hline Variables & Cronbach's Alpha \\
\hline Business Performance(BP) & 0.927 \\
\hline Cloud Computing Adoption(CCA) & 0.916 \\
\hline Trust(T) & 0.854 \\
\hline Industry Usage(IU) & 0.874 \\
\hline Technology Innovation(TI) & 0.938 \\
\hline Perceived IT Security Risk(PITR) & 0.915 \\
\hline Management Style(MS) & 0.911 \\
\hline Risk Analysis(RA) & 0.889 \\
\hline Usage of Technology(UT) & 0.892 \\
\hline
\end{tabular}

The reliability of each factor is obtained by calculating its Cronbach's alpha which should be more than 0.7.In the above table-1, all the factors Cronbach's alpha is more than the threshold value.

Table 2 : AVE and CR Calculation

\begin{tabular}{|c|c|c|}
\hline Variables & $\begin{array}{c}\text { AVE(Convergent } \\
\text { Validity) }>\mathbf{0 . 5}\end{array}$ & $\begin{array}{c}\text { CR(Composite } \\
\text { Reliability) }>\mathbf{0 . 7}\end{array}$ \\
\hline PITR & 0.874 & 0.9765 \\
\hline T & 0.8969 & 0.9716 \\
\hline CCA & 0.9098 & 0.98658 \\
\hline BP & 0.8864 & 0.9858 \\
\hline UT & 0.924 & 0.983 \\
\hline RA & 0.9218 & 0.9829 \\
\hline TI & 0.9449 & 0.99 \\
\hline IU & 0.836 & 0.966 \\
\hline MS & 0.91 & 0.9759 \\
\hline
\end{tabular}

\section{References}

[1] A.Dutta , G. Chao A. Peng, and A. Choudhary, "Risks in enterprise cloud computing: the perspective of IT experts," Journal of Computer Information Systems, vol.53. , no.4. , 2013, pp. 39-48.

[2] Peter J. Paul., "Construct validity: A review of basic issues and marketing practices," Journal of marketing research,1981,pp. 133145 .

[3] Hairs JF, Anderson RE, Tatham RL, Black WC, Multivariate data analysis, Englewood Cliffs, NJ: Printice Hall, 1998.

[4] C.Fornell and D. F. Larcker, "Evaluating structural equation models with unobservable variables and measurement error," Journal of marketing research, 1981, pp. 39-50.

[5] A.R. Peterson and Y. Kim," On the relationship between coefficient alpha and composite reliability," Journal of Applied Psychology, vol.98.,no.1., 2013, pp. 194.

[6] M.R. Baron and D. A. Kenny,"The moderator-mediator variable distinction in social psychological research: Conceptual, strategic, and statistical considerations," Journal of personality and social psychology, vol. 51.,no.6., 1986,pp. 1173.

[7] P.W. Holland, "Causal inference, path analysis and recursive structural equations models," ETS Research Report Series, 1988,pp.50.

[8] U.Sekaran, "Middle-class dual-earner families and their support systems in urban India," 1992

About Author (s):

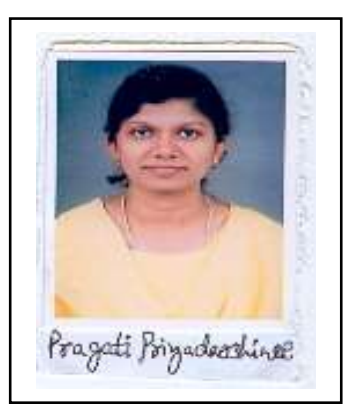

Pragati Priyadarshinee received BE from Utkal University and M.Tech (SE) degree from Indian Institute of Information Technology, Allahabad (IIITA). Her research interests include Software Engineering, Cloud Computing, Knowledge Management and Software Architecture. At present, she is a Ph.D. Research Scholar at National Institute of Industrial Engineering (NITIE). 